\title{
Chapter 6 \\ Curtailing Agriculture Projects’ Practices That Can Harm Urban Food Security and Public Health
}

\subsection{Introduction}

Many old and "modern" cities have been built on terrain that was previously vegetated and part of biologically diverse ecosystems. This was often on productive farmland that was not protected from encroachment as municipalities expanded and opened pristine areas to development. The encroachment continues as rural citizens and their families are attracted to urban centers for the way of life they seemed to offer. This starts with employment possibilities, education for workers children, and family health services as manufacturing/industrial operations and large and small businesses that serviced them spurs economic development. Agricultural projects are located mainly away from population centers, be they major metropolises or smaller cities. They provide food security for urban citizens through "brought into markets" in-ground crops, bush crops, and tree crops they cultivate, and through animal husbandry (e.g., beef and dairy cattle, poultry, hogs, sheep). The last chapter described how manufacturing/industrial endeavors can present potential harm to the health of urban and rural citizens and to natural resource rich ecosystems that help sustain them, and how to find solutions to the problems. This chapter will discuss the problems that food production methods present, the threats they pose to urban populations that are generally distant from them, and possible solutions to such problems.

It should be noted that animal husbandry range stock will cause little environmental harm if herds and flocks are properly tended. However, commercial high production operations can create massive waste-related problems (e.g., manure, urine, pathogens [e.g., salmonella, E. Coli, listeria, coronavirus, foot and mouth disease]). Added to this are the wastes of blood, innards, bones, heads, feet, skin, feathers from the slaughter and dressing of ruminants and poultry. In addition, there are the problems from the overuse of antibiotics and growth hormones (anabolic steroids) delivered to food animals via feed or patches. The overuse of antibiotics for animal husbandry may stimulate the mutation of target bacteria to antimicrobial 
strains that can resist antibiotics treatment of human bacterial infections and result in patient death. The risk to human health is a worry to the medical community [1]. World wide it was estimated that in 2014 there were 700,000 deaths attributed to microbial resistant infections [2,3]. This problem can begin to be alleviated by using antibiotics only for sick animals and not an entire herd or flock and research that focuses on medicines to kill the existing antibiotic strains. This should be coupled with the elimination of the use of growth hormones in commercial operations where food animals or food-giving animals are raised. Residues of these antibiotics and growth hormones have been found in the meats from food animals and over time can build up in consumers (billions in cities) and be dangerous to their long term health. We will discuss what governments are doing to minimize the use of chemicals in animal husbandry operations.

\subsection{Food Insecurity: Stemming Urbanization}

Many in the global population, especially babies, young children, and the aged in Africa and the Middle East suffered with chronic malnutrition and starvation from famine in 2017. This is the result of drought, people being displaced from their homes by warring factions and decisions not to allow humanitarian food supplies to reach starving populations, thus exacerbating the famine problem. If there is agricultural land that adds to the food security and it is nearby expanding cities, this land should be preserved and neither encroached upon by growing populations nor be subject to seizure by eminent domain laws for economic development. Here we have a moral question: Should cities limit population growth from in-migration and immigration to prevent encroachment? The flow of people to cities can be arrested if urban attractions are not driving forces. This means improving the services available in rural areas by subsidizing farming, increasing employment opportunities, and upgrading and increasing educational offerings. There should also be improvement in rural health care facilities with professional and support staff, and well stocked with basic medications, and with ready access to diagnostic medical equipment. This solution is easily prescribed but difficult to bring to fruition mainly for economic reasons but also by the reluctance of some trained personnel to move to rural areas such as those needed to provide professional health services. Nonetheless, a start in bringing this prescription to reality may slow urban population influx from in-migration and lessen the possible encroachment on productive land.

\subsection{Erosion Control and Water Supply/Needs}

As indicated above, it is good practice to preserve farmland near an urban center not only from population encroachment but also from processes that can degrade good agricultural soil and affect the quality and yield of food crops grown and hence 
food security. The former action requires a municipal decree that will prevent squatting and establishment of shantytowns on protected land. The latter requires that consultants assess erosion potential of farm acreage and provide solutions to prevent erosion by wind (e.g., change plow and seed method to slice and seed; plant vegetation wind breaks at peripheries of croplands) or by flowing water after heavy rains (e.g., by diversion channels to safe discharge locations) if this could be a problem. When protected land is to be used for agriculture, experts have to determine what water requirements will be for crops that are planned and consider how this might change if crops are rotated (alternated) and thus affect urban water security. Will crops be irrigated or rain fed, or be sustained by a combination of both? If irrigation is necessary, will the irrigation technique to be used preserve water supplies (e.g., drip irrigation that needs initial investment and subsequent maintenance) or will it lose precious water to evaporation during arm irrigation? Will the irrigation water come from aquifers or surface waterways? If from aquifers, is the seasonal discharge balanced by recharge so as to sustain water supplies and prevent subsidence as may occur? If subsidence were to take place, there can be additional problems that affect a population that were discussed in a previous chapter (e.g., greater susceptibility to flooding, ruptured infrastructure). In planning for the future there is the question of how will projected climate changes affect availability of the agricultural water supply over time and perhaps require changes in crops that should be grown?

\subsection{Agricultural Chemicals and GMO to Assist Growth and Protect Crops}

Food security for citizens from farm crops can be abetted by the use of agricultural chemicals (fertilizers) that replenish the nutrient content of soils depleted by a previous crop. The application of herbicides protects crops from weeds that take up nutrients while pesticides repel pests (insects, animals) that infect or consume crops. The judicious use of an optimum amount of pesticides, herbicides, and fertilizers on in-soil, bush, and tree crops will assure full growth and maximum crop yield and limit their effects on any excess that may access ecosystems. That there is no overuse is essential. It is also economically advantageous to a farmer by saving on agricultural chemicals expenses. Overuse of these chemicals can result in runoff of an excess into nearby surface waters when it rains, or after irrigation, and can also result in seepage of the chemicals and biocides into aquifers thus contaminating groundwater that may flow towards cities and be used by urbanites. Contaminated groundwater that discharges into waterways can affect the life forms inhabiting them to the detriment of society by harming an important food source. For example, runoff of nutrient rich agricultural chemicals into waterways will contribute to algal blooms that can be responsible for great fish kills (red tide) in oceans, estuaries, lakes and rivers as phytoplankton comprising the bloom die and release toxins that 
attack fish gills. Red tide also causes closure of shellfish beds for harvest and may cause skin problems and respiratory distress in people in coastal zones from wind borne toxins. As important is the fact that decomposition of dead organisms (mainly algae) in marine and terrestrial water bodies can use all of a habitat's oxygen (eutrophication) thus causing fish kills and dead zones. Such actions reduce the yield of food fish for cities and for rural coastal populations.

\subsubsection{Genetically Modified Foods}

Genetic modifications can produce seeds that may protect farm crops from weeds and repel pests that harm crops or diminish yields thereby avoiding the application of chemicals to do the job. This eliminates chemical residues on vegetables and fruits, that if not thoroughly washed, can enter the human food chain and potentially be harmful to consumers. However, ingestion of GMO grown products could be a risk to human health as suggested by controlled experiments. In these, rats developed lesions, suffered organ damage, and died after consuming GMO grown potatoes. However, a critical review of the literature suggested that the published research left an incomplete evaluation regarding the safety (toxicity) of GM crops eaten by humans and fed to animals. This is because there was no unified experimental methods so that reports could not be properly reviewed, and perhaps more important, experiments could not be repeated, a key to validation of experimental results [4]. There have been failures in GM grown corn that contributes to mutated, resistant insects that attack GM growing crops and pesticide protected crops. For example, the rootworm that infected corn developed a resistance to GMO corn treated with Bacillus thuringiensis (BT) [5, 6]. In a sense, this can be likened to the overuse of antibiotics in cattle feed consumed in feedlots that resulted in the mutation of bacteria to strains resistant to antibiotic therapy. There is the fear that during pollination of GM crops, the pollen will be carried to non-GMO fields and affect the purity of their crops. In Capulalpam, Mexico, scientists documented the discovery of transgenic genes in the Mexican native corn. In 2013 Mexico banned the entry of GM corn. It is because of uncertainty of their effects on human and animal health and food security that GM crops are not allowed in the European Union, several nations in Africa, and elsewhere. In addition, some researchers believe that there is the potential for an allergic reaction in humans from ingestion of GM based corn products. Organically grown foodstuffs obviate the chemicals or GMs problems but do not produce the mass of crops needed to feed large and growing global and urban populations as was the case for the GMO "green revolution" that allowed many countries to improve their food security. 


\subsubsection{Microbes to Protect Crops and Increase Yields}

Microbes associated with plants from biomes on all continents except Antarctica have been studied in great detail and some identified as to the characteristic they give to plants that assist agricultural projects. These have been cultured, batch produced, and used to coat seeds. The first product of this effort, Indigo Cotton ${ }^{\mathrm{TM}}$, cotton seeds coated with a proprietary mix of microbes (bacteria and fungi) were sown in West Texas in 2016. This resulted in an 11\% improvement in yield by protecting the crop against drought stress [7]. Similarly treated seeds of soy, rice, wheat and corn coated with proprietary microbe mixtures have been produced with like results. This adds to the food security of city and mega-city populations dependent on foods from outside the urban locations, complementing advances in natural hybridization and GMO that impart seed properties that protect crop yield. The company is working on microbial products that can reduce the need for nitrogen fertilizer and that offer protection against pests.

\subsection{Animal Husbandry Wastes: A Threat to Public Health and Critical Ecosystems Unless Used, Controlled, or Disposed of Securely}

The demand for food is rising worldwide with increasing populations, and where incomes are also increasing, the demand for meat is rising as well. For example, the Chinese population increased by more than 40\% from 1980 to 2015 and the income has increased significantly more. This resulted in a fivefold increase in the demand for pork. These changes put pressure on the animal husbandry industry to produce more product, ofttimes at a faster rate, using chemicals and vaccines. The problems that exist in this industrial production mode and solutions to them are discussed in the following paragraphs.

\subsubsection{Animal Husbandry Problems that Affect People}

Another major food security concern for growing urban (and global) populations are problems with animal husbandry during growth and after slaughter and distribution. It is most threatening to ecosystems close to where thousands to millions of animals are bred in close quarters (e.g., cattle feed lots and commercial chicken farms, respectively) and where they are taken for slaughter. The problems are how to capture and control the wastes and how to safely use them or dispose of them so as not to contaminate soils and waterways or aquifers. These are manure and urine from cattle (plus pigs, sheep, and goats) and fecal matter from chickens (plus ducks, 
turkeys). Added to this are slaughter house wastes (fluids [blood, wash water]) and solids (heads, innards, skins, bones, feathers), plus pathogens (e.g., salmonella, E. Coli, listeria, coronavirus, foot and mouth disease) from dressing the food animals. If these wastes are not collected and put to use by manufacturers or not disposed of securely to prevent interaction with the environment, they can pollute and diminish food production and contaminate natural resources in terrestrial and aqueous ecosystems. This may be by rainwater runoff of fecal matter rich in nutrient into food fish habitats (e.g., oceans, estuaries, rivers). The nutrient rich runoff fuels algal blooms that poison habitats (with toxins) or cause depletion of oxygen (eutrophication). As cited previously, both toxins and eutrophication can result in great fish kills. Also, leakage of pollutants in waters from animal husbandry locales into soils can contaminate crops. This might be by unregulated disposal of solid matter that allows rainwater to interact with soils and as previously noted, move dissolved contaminants into soils and by seepage through soils into aquifers thereby contaminating them. As noted in an earlier paragraph, free range stock will not cause such environmental harm when herds are properly tended (e.g., prevent overgrazing) but will have fewer but organically bred food animals to sell.

\subsubsection{The Extent of the Manure Waste Problem and Possible Solutions}

To appreciate the extent of the animal husbandry waste problem, we can examine the issue with thousands and thousands of tons of manure generated at cattle feedlots. Each head of cattle in a feedlot can drop 15-20 times the mass of manure as does one person. A lactating dairy cow can excrete $~ 44$ times a person's output [8]. Thus, a feedlot with 50,000 cattle would excrete the same mass of manure daily of about 800,000 people. There are 32 such lots licensed in Kansas, USA, state with well over 2,000,000 heads of cattle in feedlots. The sheer mass and volume of manure that has to be disposed of and well cleansed of pathogens and residues of growth hormones (anabolic steroids) and antibiotics used in animal husbandry. This can be accomplished in three ways. Done properly, this can reduce the risk of contamination of water and soils that can negatively affect food delivered to urban centers as well as clean water security, and limit the evolution of antibiotic resistant strains of bacteria that threaten the healthcare community, topics that will be treated in following paragraphs. Pigs and sheep raised in close quarters and that are infused with growth hormones and antibiotics generate masses of solid wastes that should be treated as described below for cattle.

An initial disposal method used was to spread raw manure over acreage with its contained pathogens and residues of growth hormones and antibiotics. Mobilization of these pollutants by rainwater, melting snow, or floodwater has contaminated nearby surface waters by inflow, and via leakage into soils and seepage through soils into aquifers. Ingestion of these residues from soil grown and irrigated food- 
stuffs that are not thoroughly washed can be health threatening over time to consumers (by bioaccumulation in body organs). In the end, the volume of manure generated daily overwhelmed the available acreage and required the use of other disposal methods that would not endanger people and ecosystems. Planning teams for building a new city have to determine possible health risks may originate from previous use of what appear to be good terrain for development but that may have been for animal husbandry If so, the teams have to assess how and where wastes were disposed of and the efficiency of such disposal.

One disposal method uses heat generated by manure fermentation to kill pathogens at or close to the waste accumulation site. Masses of manure are stacked up and with time ferment and heat up from within to temperatures that eliminate pathogens, growth hormones, and antibiotics ( $>131{ }^{\circ} \mathrm{F}$ but $<160{ }^{\circ} \mathrm{F}$ for 15 days). Higher temperatures will kill beneficial microbes. A problem with this method is that the high temperatures do not reach the outer edges of the stacks leaving a significant amount of the contaminants active $[9,10]$. These would have to be retreated.

Another fermentation method to cleanse cattle manure is to compost it in large rotatable drums that hold thousands of pounds of manure that are turned once a week for six weeks. This mixes and aerates the manure thus distributing the built up heat $\left(>131{ }^{\circ} \mathrm{F}\right.$ but $\left.<160{ }^{\circ} \mathrm{F}\right)$ throughout the mass eliminating $>90 \%$ of the health threatening components. In this way, the tonnage of manure changed to compost is reduced by $\sim 60 \%$. The sterilized nutrient rich manure product can be dried, bagged, and sold as fertilizer that also enhances moisture retention by soils. The manure product can also be dried, pressed into briquets and combusted to produce energy $[9,10]$. This can be an economic benefit to feedlot owners.

Chickens produce an average of 0.054 pound of manure daily [8]. A commercial operation with one million chickens would produce $27 \mathrm{lbs}$. (12 1/4 kg) of manure daily or $54 \mathrm{lbs}$. $(24.5 \mathrm{~kg}$ ) daily for two million chickens. The manure is nutrient rich (nitrogen and phosphorus) but is a carrier of disease and internal parasites. When this is spread on fields as a disposal method, runoff during rainstorms can carry the waste to discharge into productive rivers, estuaries, and oceans that may be serving the interests of urban populations. As discussed earlier, the nutrient rich matter stimulates algal and toxic dinoflagellates growth. When algae die, they decompose using oxygen in the water to the point where there is no oxygen for fish and a resulting massive fish kill including oysters and clams. When toxic dinoflagellates die, they release a neurotoxin into the water that manifests itself in the ocean as a "red tide" and millions of dead fish. This causes a break in the aqueous food web and temporarily diminishes food fish security for coastal communities (cities and towns, villages) as well as causing a temporary economic disruption for fisheries. Instead of spreading the chicken manure on fields and causing ecological and economic problems, many commercial poultry producers are composting and aging the manure for 2-3 months and then recycling it as fertilizers. The Perdue chicken producer set up a large scale controlled composting operation that has profitably processed 650,000 tons (591,000 tonnes) of chicken manure (waste from more than 48 million chickens) during 16 years to produce certified organic fertilizer [11]. 


\subsubsection{The Urine Waste Problem}

Urine from feedlots that is not captured and properly treated before discharging it at the surface can seep through soil into groundwater and contaminate it with the chemical nitrate. Groundwater carries the nitrate slowly down flow commonly at $1-5 \mathrm{ft}$. (30-150 cm) a day depending on the aquifer rock permeability. If there is a population $5 \mathrm{mi}(8 \mathrm{~km})$ down flow ("out of sight, out of mind") that uses the groundwater as its primary source, a $5 \mathrm{ft}$. a day flow rate would bring the nitrate contaminated water from a feedlot to unaware users in about 14 years. If urine input were to stop, it would take 14 years for the contaminated aquifer water to clear a municipal or individual well $5 \mathrm{mi}$ away. If the aquifer flow rate is less than the $5 \mathrm{ft}$. $(150 \mathrm{~cm}) \mathrm{a}$ day, then the time to reach a user or for contaminated water to clean the well is longer. This is a possible problem planners have to deal with. Untreated nitratelaced water can be unknowingly used to prepare baby formula and the subsequent bioaccumulation of nitrate in a baby's system has caused "blue baby sickness", a type of nitrogen narcosis. It is important for a planning team that proposes to use aquifer water for a new city or more likely redevelopment of a city to accommodate its growing population to do four things. First is to have analyses made of the water to check its potability or need for treatment. Second is to determine what projects are or were up flow and what contaminants were or could have been released as untreated effluents onto aquifer recharge areas. Remember that recharge areas are extensive so that surveys of what possible contaminant sources might be in the recharge zones or have been there in the recent past have to be broad and fairly far reaching. Third is to determine the flow rate of the aquifer water. Fourth, if treatment is necessary, planning on how to treat the water at a well site or at the tap and the cost of doing so determined. This precludes an assessment of whether a collection, treatment facility and clean water distribution network is feasible given the costs for its construction, operation, and maintenance.

A chemical element that has poisoned groundwater, sickened many, and put millions in India and Bangladesh at health risk before its presence was discovered is arsenic (As). The arsenic has nothing to do with animal husbandry but is worth mentioning here to emphasize the fact that ground water has to be analyzed at its source and along its flow path. The arsenic originated from excessive seasonal extraction of groundwater for irrigation from 20,000 tube wells during the "green" revolution. The water was used as well for drinking, cooking, and personal hygiene. Excessive pumping lowered the water table during a crop growing season and exposed the arsenic bearing mineral pyrite in the aquifer rock to oxidation that released an arsenic toxin to groundwater when recharge took place after a harvest. Once the health problems were diagnosed and related to arsenic ingestion, methods were designed to remove this toxic metal from the groundwater [12]. 


\subsection{Threats to Public Health from Growth Hormones (Anabolic Steroids) and Antibiotics Used in Animal Husbandry}

For many of the $\sim 4$ billion people living in cities/mega-cities in 2018 or of the 6.9 billion projected to inhabit them in 32 years (2050) in developed, developing, and less developed countries, meat from ruminants, foul, or fish is or will be a common food in their diets. This often comes from distant sources. Methods of production of these comestibles varies according to the standards established by health agencies charged with protecting the food supplies and security for their citizens. For some, this means disallowing the use or overuse of chemicals and/or vaccines to stimulate animal growth or as protection against diseases especially in large scale operations such as cattle feedlots, dairy farms, pig pens, commercial poultry farms, and aquaculture. This applies as well to smaller meat production set ups. Planning teams should consider food sources/security when they assess the availability of food needed to sustain people that will inhabit a purpose built city or existing cities with rapidly growing urban populations. These are discussed in the following sections.

\subsubsection{Growth Hormones Residues in Meat Products}

As important as dealing with solid and liquid wastes generated in food supply businesses is dealing with the residues from growth hormones (anabolic steroids) implanted in cattle as they enter feedlots in the United States. There are three natural and three synthetic steroids in use. At slaughter houses, these are found in measurable concentrations in beef (muscle and fat), and organ meats (e.g., liver and kidneys). These may be consumed by most urban citizens that do not opt to buy organic meat products, most often because of higher cost. In addition to beef cattle, the steroids are also allowed for use in dairy cows and sheep, but not for pigs or poultry. The use of the recombinant bovine growth hormone ( $\mathrm{rbGH}$ ) was banned in meat production in the European Union in 1988, and subsequently in Canada, Australia, New Zealand, and Japan because the rbGH gives rise in milk to IGF-1, a chemical that helps some types of cells to grow and may influence the risk of prostate, breast, or colorectal cancer $[13,14]$. Because the growth hormones cause unnatural cell growth, a phase in the development of cancer, it is incumbent on governments to further investigate banning their use in animal husbandry. Also, their ingestion by humans and possible bioaccumulation in vital organs may alter fetal development and bring about early puberty. Early puberty in young girls and breast development could be a target for unnatural cell growth and a catalyst for breast cancer [15]. There is a paucity of research reports on steroid sex hormone residues and meat consumption. However, a 2007 paper reported on meat consumption during pregnancy associated with sperm concentration and volume in sons of women in two 
groups: low meat consumption and high meat consumption. The sperm concentrations and volumes were $24.3 \%$ higher for the low meat consumption group, but for the sons of the high meat consumption group, $18 \%$ had sperm concentrations below the WHO standards threshold for sub-fertility. This was three times greater than the sons of the low meat consumption group [16]. The probable health issues that arise from the secondary ingestion of growth hormones should drive the United States Congress and regulators from other governments to increase financial support in this research field.

\subsubsection{Antibiotics Residues in Meats}

Equally important to human health in cities and villages as regards animal husbandry as well as in food producing ecosystems is the use of antibiotics in feed for cattle and other food animals raised in feedlots or other close quarters (e.g., pens, cages) and the sometimes poor hygienic condition there. In 2009 in the United States, 28.8 million lbs. (13.1 million $\mathrm{kg}$ ) of drugs were sold for livestock use and 7.2 million lbs. (3.3 million $\mathrm{kg}$ ) for human use, $\sim 80 \%$ vs. $\sim 20 \%$, respectively. Many of those antibiotics that are commonly used to treat human bacterial infections were sold and used for livestock $[17,18]$. The drugs are employed to stimulate livestock growth and to protect the enclosed animals from sickness. Medical professionals fear that the sheer volume of the antibiotics being used abets the mutation of bacteria to antibiotic resistant strains. Before mutation, antibiotics could control most pathogens that cause sickness in humans. Medical groups have suggested that antibiotic use should be limited to feedlot cattle that are sick and not to every head in the feedlot. This would spectacularly reduce the volume of antibiotics used and slow the evolution of mutated strains of antibiotic resistant bacteria. As of January 1, 2017, farmers in the United States needed a prescription or Veterinary Food Directive to use antibiotics that are important to humans. Drug resistant bacteria pose a public health threat that is not a major focus of pharmaceutical research into effective antibiotics against the resistant bacterial strains. This is likely because pharmaceutical companies are tasked to deliver maximum dividends to their stockholders. Thus, there is no heavy investment in antibiotic research that is not foreseen as yielding strong financial returns. However, to counter this, government funding in the United States and other countries is being directed to government and university research laboratories to focus on the development of drugs to be effective against the resistant bacterial strains. 


\subsection{Aquaculture}

Fin fish, mollusks, crustaceans, frogs and other aquatic animals and aquatic plants are raised in aquaculture operations. Fish is a major food/protein source for people in city and rural setting and especially for people that live in coastal communities proximate to oceans and lakes in many countries. The mass of food fish raised in aquaculture systems has been steadily increasing as ocean wild fish capture has decreased because of overfishing and enforced global legislation that reduces capture allotments in order to allow ocean fish stocks to replenish. Aquaculture now produces $50 \%$ of all seafood for human consumption [19]. By 2030, the aquaculture production is projected to reach $62 \%$ of all food fish [20]. As such it is important for planning to ensure first that food security from this source can be sustained to help feed annually increasing city and global populations and second that aquaculture products are safe to consume. Aquaculture has similar problems as agriculture when growth hormones (anabolic steroids), antibiotics, or in this case water treatment chemicals are used in the operation. Also, care must be taken to assure that the chemicals and fish feces from containerized pools (tanks) that constantly build up are regularly removed and treated before subsequent discharge into the environment. The dirty waters, if discharged untreated into waterways may be detrimental to the safe human use of water from them and may also affect life forms there by causing mutations or by killing them. In well planned special projects the dirty water may be used as part of a looped project.

\subsubsection{A Looped Project in Eritrea}

An example of a looped project in the Eritrean coastal desert begins with a $5 \mathrm{~km}(3$ mi) long canal that brings Red Sea water into concrete lined shrimp tanks to prevent leakage into surface ecosystems or the underlying aquifer. The shrimp species (Penaeus vannamel) and Indian prawn (Penaeus indicus) tolerate changes in salinity temperature, $\mathrm{pH}$, and oxygen. The sea water from the tanks is then channeled into three salt lakes for aquaculture cultivation of Tilapia and milk fish (Chanos chanos) for food and to make products including shrimp feed from recycled fish heads. Waste from the lakes, rich in organic nutrients, is carried by water to fertilize Salicornia farming. Salicornia is a succulent plant that can grow normally in fields irrigated with salt water. Its seeds are pressed to give oil and young shoots of Salicornia are exported to Europe where they are considered a gourmet vegetable. The waste from Salicornia is used to make particle board, firebrick, and animal fodder. The seawater then seeps into the soil and flows back to the Red Sea. Although the looped process worked well, the business was not economically profitable because of management problems and lack of enough production to meet demand. Development of sustainable aquaculture in coastal Eritrea and other countries can contribute significantly to urban centers protein rich food supplies and is ongoing [21]. 


\subsubsection{Aquaculture in Ocean/Estuarine Waters}

Net-penned fish aquaculture (plus shellfish [shrimp, oysters], algae) in estuarine and nearshore ocean environments that allows free water exchange with the pens has a lesser ecosystem waste problem than the contained pseudo ecosystems. However, if the fish have been genetically modified to stimulate growth and prevent disease, there is the problem of escape from a pen and interaction with wild species that may negatively alter the wild species genome.

Aquaculture products should be checked periodically by certified consultants to detect any unhealthy contents of chemicals in their flesh in the same way ocean food fish (e.g., tuna, swordfish, tilefish, king mackerel, shark) are tested for mercury (a neurotoxin). Results would then be subject to recommendations made by the medical community for rate of consumption as is the case for mercury in the species named above.

\section{References}

1. Chang, Q., Wang, W., Regev-Yochay, G., Lipsitch, M., \& Hanage, W. P. (2015). Antibiotics in agriculture and the risk to human health: How worried should we be? Evolutionary Applications, 8, 240-247. https://doi.org/10.1111/eva.12185.

2. HM Government and Wellcome Trust. (2014). O'Neill, J., Chair. Review on antimicrobial resistance. Antimicrobial resistance: Tackling a crisis for the health and wealth of nations. $15 \mathrm{p}$.

3. Katrime Integrated Health. (2016). The role of human health and animal health in antimicrobial resistance. National Collaborating Centre for Infectious Diseases, 13 p. Online www. nccid.ca/publications/role-human-health-animal-health-antimicrobial-resistance

4. Zdziarski, I. M., Edwards, J. W., Carman, J. A., \& Haynes, J. I. (2014). GM crops and the rat digestive tract: A critical review. Environment International, 73, 423-433. https://doi. org/10.1016/j.envint.2014.08.018.

5. Tabashnik, B., \& Carriere, Y. (2017). Insect resistance to transgenic crops: Second decade surge and future prospects. Nature Biotechnology, 35, 926. https://doi.org/10.1038/nbt.3974.

6. University of Arizona. (2017). Pest resistance to biotech crops surging. Summary of above reference. In Science Daily, Oct. 10. Unpaginated.

7. Shaw, J. (2018). A new green revolution? Harvard Magazine, March-April, pp. 44-48.

8. Fleming, R., \& Ford, M. (2001). Humans versus animals - Comparison of waste properties. 4 p. Online. www.ridgetown.com/research/documents/f;eming_huvsanim0107.PDF

9. Alberta, Agriculture and Forestry. (2005). Manure composting manual. Unpaginated, Online. www1.agric.gov.ca/\%24department/deptdocs.nsf/all/agdex 8875

10. Augustin, C., \& Rahman, S. (2010). Composting animal manures: A guide to the process and management of animal manure compost. North Dakota State University, 8 p. Online. www. ag.ndsu.edu/manure/documents/nm/478.pdf

11. The Daily Record. (2017, November 9). Perdue farms now selling recycled poultry manure as fertilizer. Online. After Associated Press, 2011, May 10. thedailyrecord.com/2011/05/10/ perdue-farms-now-selling-recycled-poultry-manure-as-fertilizer/

12. Nickson, R. T., McArthur, J. M., Ravencroft, P., Burgess, W. G., \& Ahmed, K. M. (2000). Mechanism of arsenic release to groundwater, Bangladesh and West Bengal. Applied Geochemistry, 15, 403-413. 
13. American Public Health Association. (2009). Opposition to the use of hormone growth promoters in beef and dairy cattle production. Policy No. 20098.

14. American Cancer Society. (2014). Recombinant bovine growth hormone. Online. www.cancer.org/cancer/cancer-causes/recombinant-bovine-growth-hormone.html

15. Aksglaede, L., Sorensen, K., Petersen, J. H., Shakkebaek, N. E., \& Juul, A. (2009). Recent decline in age at breast development: The Copenhagen puberty study. Pediatrics, 123, e933-e939.

16. Swan, S. H., Liu, F., Overstreet, J. W., Brazil, C., \& Shakkebaek, N. E. (2007). Semen quality of fertile US males in relation to their mothers' beef consumption during pregnancy. Human Reproduction, 22, 1497-1502. https://doi.org/10.1093/humrep/dem068.

17. Hollis, A., \& Ahmed, Z. (2013). Preserving antibiotics rationally. New England Journal of Medicine, 369, 2474-2476.

18. Katrime Integrated Health. (2016). The role of human health and animal health in antimicrobial resistance. Winnipeg, MN: National Collaborating Centre for Infectious Diseases $13 \mathrm{p}$.

19. NOAA. (2012) Fisheries. Online. www.nmfs.noaa.gov/aquaculture/faqs/faq_aq_101.html

20. World Bank. (2013). Fish to 2030 - Prospects for fisheries and aquaculture. World Bank report no. 83177-GLB, $80 \mathrm{p}$.

21. Habte-Tsion, H. M. (2016). Sustainable aquaculture development and its role in the food security and economic growth in Eritrea: Trends and prospects. Presented at the International Conference on Eritrean Studies, July 21, Asmara, Eritrea. 9 Sections. Online. www.eritreaembassy-japan.org/data/Aquaculture-Development.pdf 